\title{
Lipid absorption, bile acids, and cholesterol metabolism in patients with chronic liver disease
}

\author{
T. A. MIETTINEN ${ }^{1}$ \\ From the Third Department of Medicine, University of Helsinki, Helsinki, Finland
}

SUMMARY Faecal bile acids and neutral sterols of cholesterol origin were decreased in patients with chronic liver disease, while urinary bile acids were constantly, but never greatly, increased. Thus, production of cholesterol and its conversion to bile acids was decreased in these patients. Faecal fat was only slightly increased, even in cases with a very low bile salt output, but it was negatively correlated with faecal bile acids. The reduced capacity of these patients to synthesize bile acids was shown by the fact that cholestyramine treatment, although it decreased urinary bile acids, increased faecal bile acids only slightly. The resin constantly increased faecal neutral sterols, while the increase of faecal fat was insignificant. Thus, the absorption of fats, as compared with that of sterols, was less strongly reduced by interruption of the enterohepatic circulation of bile salts. In one cirrhotic patient markedly increased faecal bile acids apparently caused cholerrhoeic diarrhoea, which was easily controlled with cholestyramine. The latter consistently increased elimination of cholesterol in cirrhotic patients, but serum cholesterol was not consistently decreased, and in these patients, in contrast to the control subjects, it was difficult to detect changes in cholesterol synthesis with the acetate-mevalonate test and serum methyl sterols.

In liver cirrhosis, though intraluminal micellar solubilization of lipids is frequently impaired (Badley, Murphy, Bouchier, and Sherlock, 1970; Miettinen and Siurala, 1967, 1971), fat malabsorption is usually only mild or moderate (Losowsky and Walker, 1969). The absence of the micellar phase does not necessarily lead to gross steatorrhoea, presumably owing to the relatively effective absorption of free fatty acids along the whole small intestine (Hofmann, 1966; Morgan and Borgström, 1969). Some workers have suggested that impaired micelle formation in liver cirrhosis is due to impaired bile salt production, resulting in a low intestinal concentration of bile salts during fat digestion (Badley et al, 1970; Miettinen and Siurala, 1967, 1971). Others claim that bile salt production is normal in liver cirrhosis and that neither deficient output nor low intestinal concentration of bile salts are responsible for the steatorrhoea in this disease (Turnberg and Grahame, 1970; Bode, Goebell, and Kehl, 1971). Although Blum and Spritz (1966) studied the turnover rate and pool size of ${ }^{14} \mathrm{C}$-cholic

${ }^{1}$ Address for correspondence: Tatu A. Miettinen, Third Department of Medicine, University of Helsinki, 00290 Helsinki 29, Finland.

Received for publication 28 June 1972. acid, apart from some preliminary studies (Miettinen, $1970,1971 \mathrm{a})$, no information is available on the capacity of cirrhotic subjects to produce bile acids under basal conditions and during interruption of the enterohepatic circulation. In the present investigation bile salt production was measured directly by determining faecal and urinary excretion before and during cholestyramine treatment, faecal fat and faecal nautral sterols being taken as indicators of lipid absorption and of bile salt deficiency. Compensatory changes in cholesterol synthesis to balance for cholestyramine-induced loss of cholesterol as bile acids and sterols was measured with the acetatemevalonate test and serum methyl sterols (Miettinen, 1970; 1971b).

\section{Materials and Methods}

\section{PATIENTS}

The material (Table I) comprises 11 patients with cirrhosis of the liver (one with primary biliary cirrhosis) and four patients with chronic hepatitis; cases 1 and 9 suffered from persistent and cases 8 and 14 from aggressive chronic hepatitis. The diagnosis was confirmed by histological examination of liver biopsy specimens obtained by percutaneous puncture 


\begin{tabular}{|c|c|c|c|c|c|c|c|c|c|c|c|c|c|}
\hline \multirow{3}{*}{$\begin{array}{l}\text { Case } \\
\text { No. }\end{array}$} & \multirow{3}{*}{$\begin{array}{l}\text { Age } \\
(y r)\end{array}$} & \multirow{3}{*}{$\begin{array}{l}\operatorname{Sex} \\
(m / f)\end{array}$} & \multicolumn{2}{|c|}{ Body Weight } & \multirow{2}{*}{\multicolumn{2}{|c|}{$\begin{array}{l}\text { Serum Lipids } \\
-(\mathrm{mg} / 100 \mathrm{ml})\end{array}$}} & \multirow[t]{3}{*}{$A S$} & \multirow{3}{*}{$\frac{T A L A T}{(I \mu U / m l)}$} & \multirow[t]{3}{*}{ AFOS } & \multirow{3}{*}{$\begin{array}{l}\text { Bilirubin } \\
(\mathrm{mg} / 100 \mathrm{ml})\end{array}$} & \multicolumn{2}{|c|}{ Protein $(\mathrm{g} / \mathrm{l})$} & \multirow[t]{3}{*}{ Diagnosis } \\
\hline & & & \multirow{2}{*}{$k g$} & \multirow{2}{*}{ relut. } & & & & & & & Albumin & $\gamma$ Globulin & \\
\hline & & & & & Cholesterol & Triglycerides & & & & & & & \\
\hline 1 & 56 & $\mathbf{f}$ & 56 & 0.98 & 177 & 73 & 20 & 16 & 47 & 1.7 & $33 \cdot 6$ & $20 \cdot 4$ & Hepatitis chronic \\
\hline 2 & 39 & $\mathrm{~m}$ & 84 & $1 \cdot 29$ & 211 & 76 & 30 & 17 & 25 & $2 \cdot 1$ & $32 \cdot 8$ & $44 \cdot 2$ & Cirrhosis (alcoholic) \\
\hline 3 & 33 & f & 54 & 1.08 & 260 & 63 & 18 & 18 & 29 & 0.5 & 36.7 & $7 \cdot 2$ & Cirrhosis(idiopathic) \\
\hline 4 & 26 & f & 53 & 1.02 & 206 & 70 & 8 & 11 & 21 & 0.6 & 43.0 & 6.0 & Cirrhosis (Wilson) \\
\hline 6 & 59 & f & 61 & $1 \cdot 20$ & 264 & 108 & 27 & 18 & 27 & 0.7 & $39 \cdot 5$ & 11.9 & Cirrhosis(idiopathic) \\
\hline 7 & 60 & $\mathrm{~m}$ & 50 & 0.88 & 111 & 140 & 9 & 12 & 49 & 0.5 & 43.9 & $14 \cdot 1$ & Cirrhosis(idiopathic) \\
\hline 8 & 53 & $f$ & 51 & 1.06 & 200 & - & 58 & 64 & 73 & 23.6 & $37 \cdot 0$ & 9.5 & Hepatit is chronic \\
\hline 9 & 56 & f & 66 & $1 \cdot 32$ & 147 & - & 17 & 11 & 83 & 0.9 & $37 \cdot 2$ & $20 \cdot 2$ & Hepatitis chronic \\
\hline 10 & 19 & f & 61 & $1 \cdot 13$ & 169 & 120 & 41 & 33 & 67 & 1.4 & 35.6 & 40.6 & Cirrhosis(idiopathic) \\
\hline 11 & 60 & m & 61 & 0.95 & 139 & 75 & 38 & 54 & 129 & $1 \cdot 3$ & $27 \cdot 8$ & $18 \cdot 6$ & Cirrhosis(alcoholic) \\
\hline 12 & 53 & $\mathrm{~m}$ & 55 & 0.82 & 150 & 72 & 21 & 15 & 85 & $2 \cdot 0$ & $24 \cdot 5$ & 18.9 & Cirrhosis (alcoholic) \\
\hline 13 & 62 & $\mathrm{~m}$ & 55 & 0.90 & 649 & 235 & 28 & 49 & 338 & $26 \cdot 6$ & 30.6 & 10.7 & Biliary cirrhosis \\
\hline 14 & 41 & f & 50 & 0.93 & 289 & 136 & 28 & 40 & 195 & 0.5 & $40 \cdot 3$ & $18 \cdot 6$ & Hepatitis chronic \\
\hline
\end{tabular}

Table I Clinical and laboratory observations on the patients studied

ASAT $=$ asparagine aminotransferase; ALAT $=$ alanine aminotransferase; AFOS $=$ alkaline phosphatase (normal values $\leqslant 50 \mathrm{I} \mu / \mathrm{ml})$.

or in connexion with laparoscopy or laparotomy. None of the patients with chronic hepatitis had Au-antigen in blood or antinuclear antibodies. At the time of study, liver function was relatively well compensated in most of the patients, none of whom exhibited signs of hepatic coma. Case 15 was comatose when admitted four weeks before the study. From the liver function tests available (see Table I), increased alkaline phosphatase was assumed to signify biliary obstruction. Therefore, the series was divided into two groups according to whether alkaline phosphatase was normal, below 50 international (I) $\mu \mathrm{U} / \mathrm{ml}$ (cases 1-7), or raised above 50 I $\mu \mathrm{U} / \mathrm{ml}$ (cases 8-15).

\section{STUDIES}

The patients were placed on a low-cholesterol $(125 \mathrm{mg} / 2400 \mathrm{kcal})$ solid food diet, containing $80 \mathrm{~g}$ of fat (equal amounts of lard and soybean oil) per $2400 \mathrm{kcal}$. Unabsorbable $\mathrm{Cr}_{2} \mathrm{O}_{3}$ and $\beta$-sitosterol (containing, according to analysis, $85 \% \beta$-sitosterol), $600 \mathrm{mg}$ of each divided into three daily doses, were given so that corrections could be made respectively for faecal flow and degradation of cholesterol during intestinal transit (Grundy, Ahrens, and Salen, 1968). Gas-liquid chromatographic (GLC) analysis of dietary sterols indicated that the average total intake of $\beta$-sitosterol was $620 \mathrm{mg} / \mathrm{day}$. After the patients had been on the diet, $\mathrm{Cr}_{2} \mathrm{O}_{3}$ and $\beta$-sitosterol for five to seven days, two to three three-day faecal collections were made. Thereafter cholestyramine (Cuemid), 32g/day (given for seven patients), was started for 10 days and stool collections were continued.

Cholesterol synthesis was measured by the sterol balance technique and cholestyramine-induced changes in it by the acetate-mevalonate test and serum methyl sterols, in addition. Sterol balance, which in the steady state is equal to cholesterol synthesis, was given by the difference between dietary cholesterol and faecal end products of cholesterol metabolism, viz, the sum of faecal bile acids and faecal neutral sterols of cholesterol origin. Since bile acids are often lost in substantial amounts in the urine in hepatic cirrhosis, urinary bile acids were measured in eight patients on and off cholestyramine. The acetate-mevalonate test was performed before and at the end of the cholestyramine period by intravenous injection of a small amount of a ${ }^{14} \mathrm{C}$-acetate- ${ }^{3} \mathrm{H}$-mevalonate mixture (containing $20 \mu \mathrm{Ci}$ of ${ }^{14} \mathrm{C}$ and $10 \mu \mathrm{C}$ of $\left.{ }^{3} \mathrm{H}\right)$. The ratio ${ }^{14} \mathrm{C} /{ }^{3} \mathrm{H}$ in serum cholesterol was measured and it was considered to reflect the activity of cholesterol synthesis between acetate and mevalonate. Though this method does not measure cholesterol production in terms of $\mathrm{mg} / \mathrm{day}$, the magnitude of the ratio and the changes in it have been shown to parallel cholesterol production in many clinical conditions even in non-steady states (Miettinen, 1970, 1971b, c). Serum non-esterified methyl sterols, the precursors of cholesterol, have also been shown to reflect changes in cholesterol synthesis, particularly when expressed per unit of free cholesterol, so as to eliminate the effect of variable lipoprotein levels on methyl sterol concentration (Miettinen, 1970, 1971b, c). Therefore, non-esterified methyl sterols and free cholesterol were also measured before and at the end of cholestyramine treatment.

Since there was no justification for performing sterol balance studies, acetate-mevalonate tests, or serum methyl sterol determinations either before or during cholestyramine treatment in normolipidaemic control subjects, hyperlipidaemic (both hyper- 
glyceridaemic and hypercholesterolaemic) patients with normal liver function served as a control group for the cholestyramine experiments (Miettinen, 1971b). Owing to obesity, some of these subjects exhibited high cholesterol production, the hypercholesterolaemic patients tending to have subnormal values.

\section{CHEMICAL ANALYSES}

Serum cholesterol (Pearson, Stern, and McGavack, 1953) and triglycerides (Carlson, 1963) were determined during basal faecal collections, non-esterified cholesterol being measured in connexion with quantification of methyl sterols (Miettinen, 1971b). The latter was performed by GLC after the methyl sterols had been separated by thin-layer chromatography (TLC) from the other lipid classes (including free cholesterol) in the chloroform methanol extract of serum. The ratio ${ }^{14} \mathrm{C} /{ }^{3} \mathrm{H}$ of the acetate-mevalonate test was measured from the total serum cholesterol in the non-saponifiable material (Miettinen, 1970, 1971b). Faecal bile acids, neutral steroids, and dietary sterols were analysed by GLC (Grundy, Ahrens, and Miettinen, 1965; Miettinen, Ahrens, and Grundy, 1965), faecal fat according to the methods of van de Kamer, ten Bokkel Huinink, and Weyers (1949), and chromium as suggested by Bolin, King, and Klosterman (1952). Since no loss of $\beta$-sitosterol was found during intestinal transit (recovery of dietary plus administered $\beta$-sitosterol in the faeces was complete in every case) the faecal values are expressed in terms of $\mathrm{Cr}_{2} \mathrm{O}_{3}$. For this purpose the amount of steroid or fat per $\mathrm{mg}$ of $\mathrm{Cr}_{2} \mathrm{O}_{3}$ in the faeces was multipled by 600 . Urinary bile acids were measured in essentially the same way as in the faeces, except that they were solvolysed before alkaline hydrolysis (Palmer, 1967) and that a $1 \%$ NGS (neopentyl glycol succinate) column was used for GLC analysis instead of the DC-560 column employed for the quantification of total faecal bile acids. Identification of urinary cholic acid, deoxycholic acid, chenodeoxycholic acid, and lithocholic acid depended on identity of the retention times of the trimethyl silyl derivatives of these bile acids with those of the references in the GLC run, and on mass spectrometry in a combined gas chromatography-mass spectrometry instrument (LKB-9 000) equipped with a $1 \%$ NGS column (Miettinen and Luukkainen, 1968).

\section{Results}

FAECAL FAT

As compared with the control subjects patients with liver diseases had increased excretion of faecal fat (Table II). Faecal fat was not significantly higher in the patients with raised than with normal alkaline phosphatase levels.

\section{FAECAL STEROIDS}

The amounts of faecal bile salts and neutral sterols were low in the patients with liver diseases (Table II). Since urinary bile salts (Tables II and III) contributed relatively little to bile salt excretion it can be concluded that in cirrhotic patients, especially in those with high alkaline phosphatase, bile acid synthesis is significantly reduced. Patient 7 , with advanced but compensated cirrhosis, had a surprisingly high faecal and urinary bile acid output and low serum cholesterol; the other patients with normal alkaline phosphatase had quite low faecal bile salt values.

Faecal bile acids showed a positive correlation with neutral sterols $(r=0.52)$ under basal conditions but tended to be negatively correlated with faecal fat $(r=-0.49$; significant on $\log -\log$ scale, $r=$ $-0.73)$ which in turn was negatively correlated with basal faecal neutral sterols $(r=-0.57)$. Thus, it seems likely that under these basal conditions (low dietary cholesterol) the amount of faecal neutral sterols is determined mainly by the magnitude of biliary secretion of cholesterol, defective absorption, indicated by slightly impaired fat absorption, being a contributory factor.

\section{URINARY BILE ACIDS}

In normal urine only negligible amounts of bile acids $(<2 \mathrm{mg} /$ day $)$ were detected, the secondary bile acids (deoxycholic and lithocholic) comprising more than half, and cholic and deoxycholic acids about half of the total (Table III). In patients with liver disease urinary excretion of bile acids was markedly increased (Tables II and III), the proportion of secondary bile acids being subnormal. The sum of lithocholic and chenodeoxycholic acids (the former is formed from the latter by intestinal bacteria) comprised $50 \%$ or more of the total bile acids in six out of eight patients and in three out of eight controls. There was no correlation between urinary bile salts and serum alkaline phosphatase. The largest amount $(33.6 \mathrm{mg} /$ day) was seen in the patient (no. 7) who had the highest faecal loss of bile acids without detectable signs of biliary obstruction.

\section{SERUM CHOLESTEROL}

The low mean sterol balance value of the patients indicates that cholesterol synthesis (and elimination) was subnormal in liver cirrhosis (Table II). Serum cholesterol (Table I) was frequently within normal limits. In some cases, however, the values were elevated, while in some others they were lowered, 


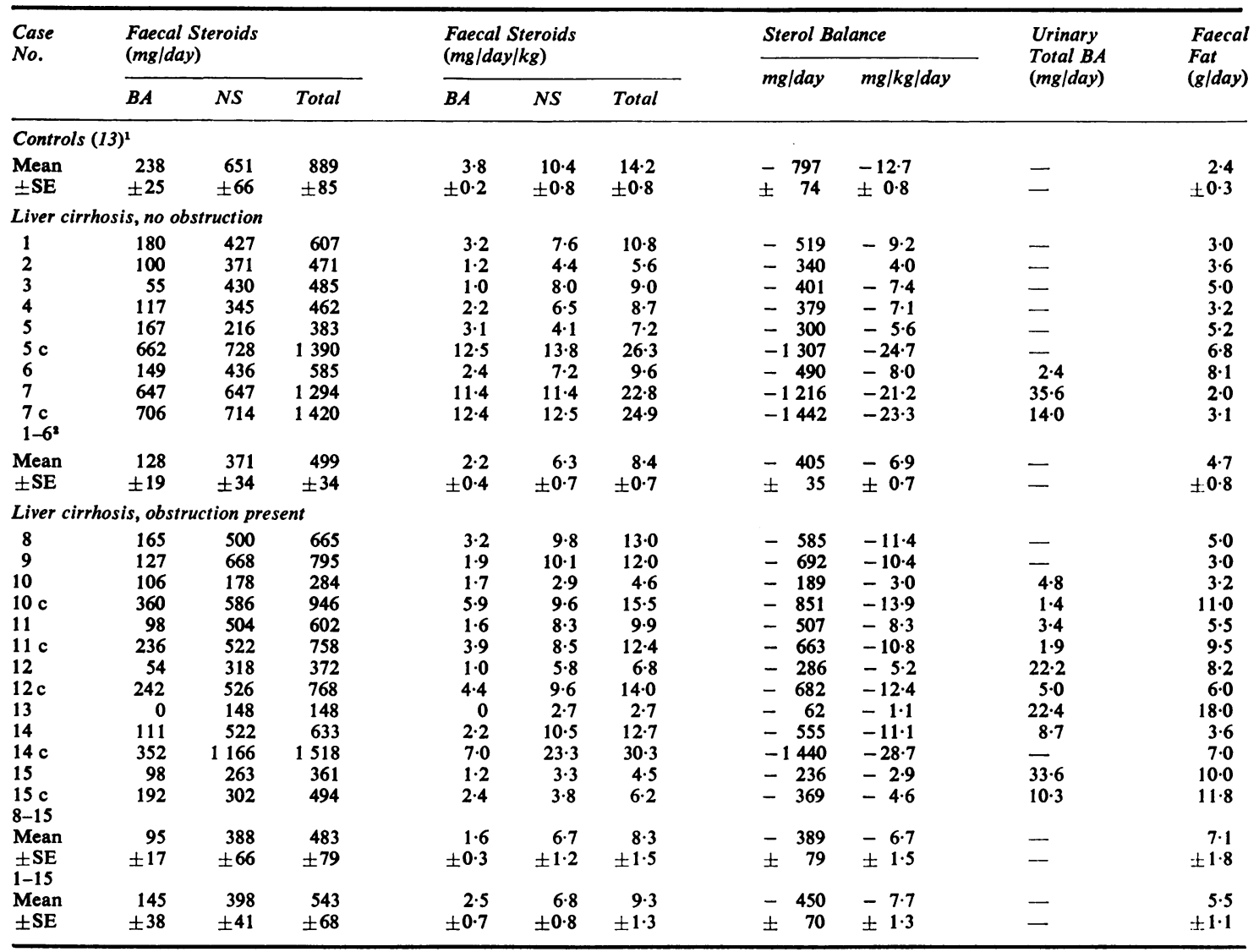

Table II Faecal fat and steroids and urinary bile acids before and during cholestyramine treatment in patients with liver diseases

$c=$ during cholestyramine treatment. ${ }^{1}$ Unpublished results on normolipidaemic non-obese subjects. ${ }^{2}$ Case 7 with interrupted enterohepatic circulation of bile acids is not included. $\mathbf{B A}=$ bile acids; $\mathbf{N S}=$ neutral sterols.

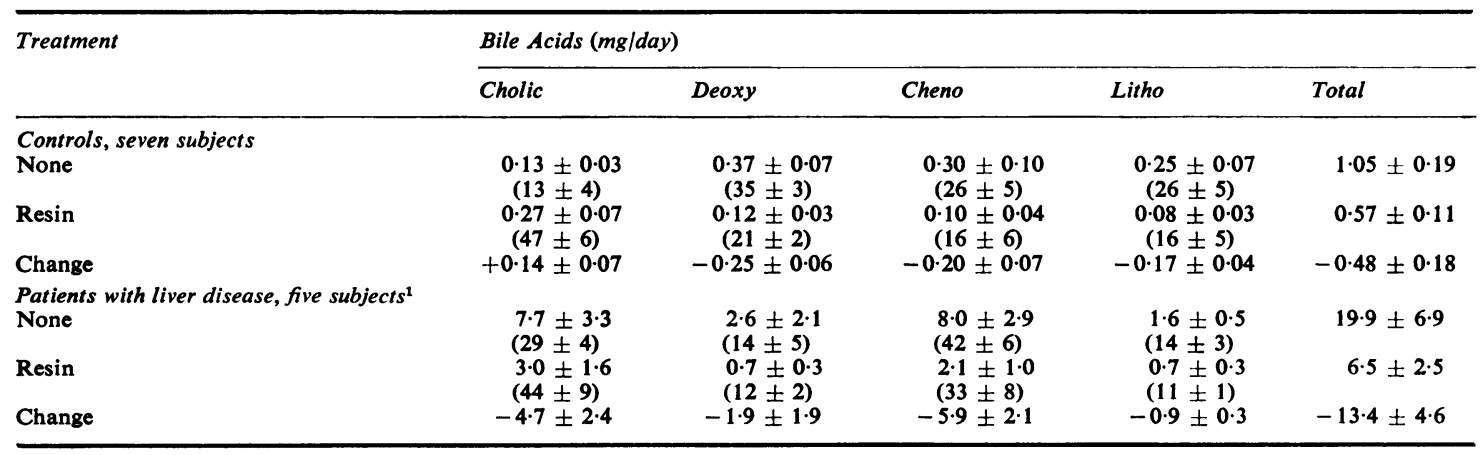

Table III Urinary bile acids before and during cholestyramine therapy in control subjects and patients with liver diseases

Figures in parentheses show the percentage distribution. ${ }^{1}$ Values from patients indicated in Table II. 
indicating that the production and elimination of cholesterol were not always decreased proportionately. In case 7 excessively increased elimination of cholesterol into faeces primarily as bile acids (Table II) was not sufficiently offset by enhanced production, resulting in low serum cholesterol. No correlation was found between the serum cholesterol and sterol balance values.

\section{EFFECTS OF CHOLESTYRAMINE}

In the patients the resin increased the faecal bile acids (Table IV) subnormally, by $210 \mathrm{mg} /$ day as compared with $957 \mathrm{mg} /$ day in the controls, indicating that the capacity of cirrhotic patients to produce bile acids is limited. This is caused initially by impaired synthesis and/or excretion of bile acids. In the patients with liver diseases, in contrast to the controls, cholestyramine consistently raised faecal neutral sterols, but, despite the increase, the total elimination (sum of faecal neutral and acidic steroids) was clearly below normal. A positive correlation $(r=0.75)$ was found between the increments of faecal bile acids and neutral sterols (Fig. 1). Despite the apparent decrease in cholesterol absorption induced by the resin, fat absorption was not consistently altered, as indicated by the insignificant increase in faecal fat; the latter was raised, however, in six out of seven studies (Fig. 1). Patient no. 7 , in whom faecal bile acids were initially increased and who presented with diarrhoea, ceased to suffer from this symptom when given cholestyramine. Yet the latter had virtually no effect on the sum of his faecal plus urinary bile acids, because the production of bile acids was apparently maximally stimulated by interruption of the enterohepatic circulation of bile acids.

Treatment with the resin reduced urinary bile acids by factors of 2 and 3 in the controls and patients, respectively, yet normal values were not reached in the latter. In the controls reduction was

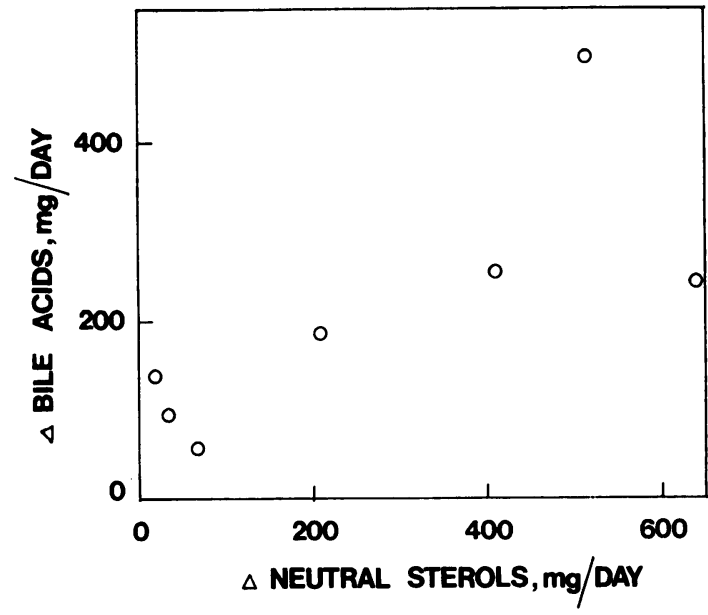

Fig. 1. Correlation between the changes in faecal bile acids and neutral sterols caused by cholestyramine in patients with liver disease. Cases treated are indicated in Table II $(r=0 \cdot 75)$.

most marked in the secondary bile acid fraction, and cholic acid even tended to increase, whereas in the group with liver disease primary and secondary bile acids were affected similarly.

Despite the increased cholesterol elimination as bile acids and neutral sterols in patients on cholestyramine, serum cholesterol (both free and esterified, shown for the former in Table $V$ ) remained unchanged. In the initial acetate-mevalonate test the ratio ${ }^{14} \mathrm{C} /{ }^{3} \mathrm{H}$ was within the control range, which, in view of the low sterol balance value, suggests that the low overall cholesterol production was not specifically due to low activity between acetate and mevalonate. The test did not reveal any significant change in cholesterol synthesis in

\begin{tabular}{|c|c|c|c|c|}
\hline \multirow[t]{2}{*}{ Treatment } & \multicolumn{3}{|c|}{ Faecal Steroids (mg/day, mean $\pm S E$ ) } & \multirow{2}{*}{$\begin{array}{l}\text { Faecal Fat } \\
\text { (g/day) }\end{array}$} \\
\hline & Bile Acids & Neutral Steroids & Total & \\
\hline $\begin{array}{l}\text { Hyperlipidaemic controls }(15) \\
\text { None } \\
\text { Resin } \\
\text { Change }\end{array}$ & $\begin{aligned} 325 & \pm 53 \\
1282 & \pm 135 \\
+957 & \pm 130^{1}\end{aligned}$ & $\begin{array}{r}634 \pm 51 \\
651 \pm 51 \\
+17 \pm 20\end{array}$ & $\begin{array}{c}959 \pm 85 \\
1933 \pm 156 \\
+974 \pm 134^{1}\end{array}$ & $\begin{array}{r}3.6 \pm 0.6 \\
4.1 \pm 0.7 \\
+0.5 \pm 0.8\end{array}$ \\
\hline $\begin{array}{l}\text { Patients with liver diseases (7) } \\
\text { None } \\
\text { Resin } \\
\text { Change }\end{array}$ & $\begin{aligned} 183 & \pm 78 \\
393 & \pm 79 \\
+210 & \pm 55^{1,2}\end{aligned}$ & $\begin{aligned} 378 & \pm 68 \\
649 & \pm 102 \\
+271 & \pm 95^{1,8}\end{aligned}$ & $\begin{array}{c}561 \pm 132 \\
1042 \pm 151 \\
+481 \pm 141^{1,2}\end{array}$ & $\begin{array}{r}5.4 \pm 1 \cdot 1 \\
7.9 \pm 1 \cdot 2 \\
+2 \cdot 5 \pm 1 \cdot 2\end{array}$ \\
\hline
\end{tabular}

Table IV Effect of cholestyramine on faecal steroids and fat in hyperlipidaemic control subjects and in patients with liver diseases

Number of subjects in parentheses. Patients treated with cholestyramine are indicated in Table II. Significant (P $<0.05)$ changes indicated by ${ }^{\prime}$ and changes significantly different from controls by ${ }^{2}$. 


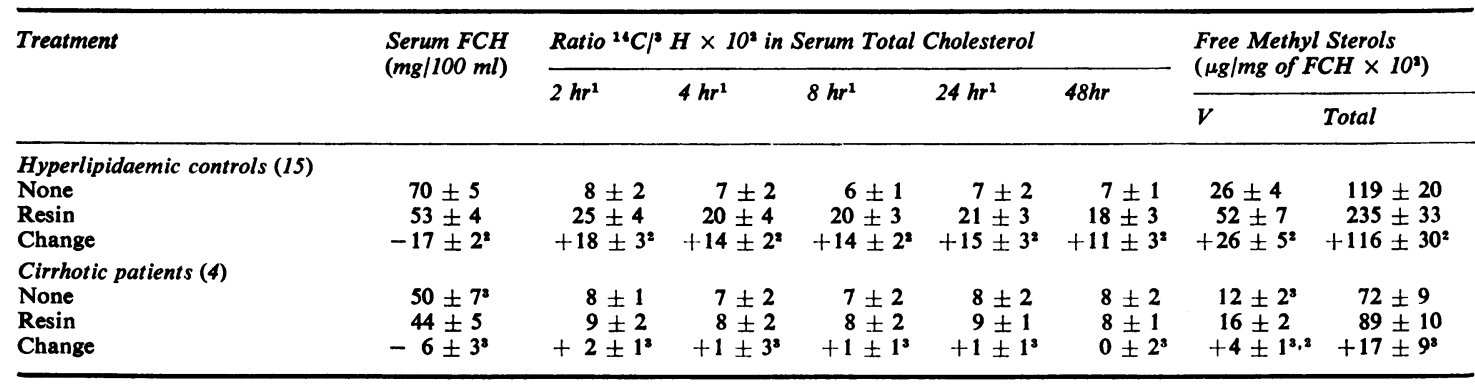

Table V Effect of cholestyramine on serum cholesterol and cholesterol synthesis in control subjects and in patients with liver diseases

Number of patients in parentheses. ${ }^{1} \mathrm{Hours}$ after iv injection of a ${ }^{14} \mathrm{C}$-acetate- ${ }^{-3} \mathrm{H}$-mevalonate mixture. Statistically significant changes (P $<0.05$ ) indicated by ${ }^{2}$ and differences from controls by ${ }^{3}$. The acetate-mevalonate test was performed in cases $7,11,14$, and 15 ; methyl sterols were measured in all cholestyramine-treated patients; $V=$ diunsaturated dimethylsterol; total methyl sterols are the sum of five subfractions found in the serum methyl sterol mixture by GLC; FCH $=$ free cholesterol.

response to cholestyramine, though in the controls a threefold increase was seen in the ratio ${ }^{14} \mathrm{C} /{ }^{3} \mathrm{H}$, suggesting that the production of cholesterol was enhanced between acetate and mevalonate by a factor of 3 (Table V). The initial methyl sterol levels were significantly lower in the patients than in the controls, the increase during cholestyramine also being significantly lower in the former than in the latter, as if synthesis of cholesterol had been relatively little stimulated by the resin in the patients with liver diseases as compared with the controls.

\section{Discussion}

\section{FAT AND STEROL ABSORPTION}

Micellar solubilization of the hydrolysis products of triglycerides with the aid of bile acids greatly promotes but is not essential for their absorption (Hofmann and Borgström, 1964; Hofmann, 1966; Morgan and Borgström, 1969). However, absorption of cholesterol requires the presence of bile acids (Siperstein, Chaikoff, and Reinhardt, 1952). Therefore, in view of the low intestinal bile salt concentration in patients with liver cirrhosis during fat digestion (Badley et al, 1970; Miettinen and Siurala, 1967, 1971) increases in faecal fats, and especially in neutral sterols, are to be expected. Fat loss, which was negatively correlated with faecal bile acids (and ultimately with synthesis of bile acids, because they are only present in small amounts in urine), was actually slightly increased but, even in case 13, in which biliary occlusion was apparently complete, it was only moderate, indicating that relatively large amounts of dietary fats had been absorbed. Administration of cholestyramine, which presumably further reduced the effective intraluminal bile salt concentration, did not consistently increase faecal fat, further strengthening the view that at least at a relatively low level of fat intake fat absorption proceeds quite effectively, provided pancreatic function and the intestinal mucosa are intact. Pancreatic insufficiency has been suggested to contribute to the steatorrhoea of liver cirrhosis by impairing lipolysis, while mucosal damage is rarely seen (cf Losowsky and Walker, 1969). Complete exclusion of bile flow usually causes only moderately reduced fat absorption in man (Porter, Saunders, Tytgat, Brunser, and Rubin, 1971) or experimental animals (Shapiro, Koster, Rittenberg, and Schoenheimer, 1936; Morgan and Borgström, 1969). In clinical biliary obstruction fat absorption ranges from 45 to $90 \%$ (Atkinson, Nordin, and Sherlock, 1956).

Cholesterol absorption has not been istudied in patients with liver cirrhosis. Since the diet given to the patients of the present study was quite low in cholesterol, most of the faecal neutral sterols must have originated from the bile or intestinal mucosa. The amount eliminated by the mucosa is unknown, particularly because mucosal synthesis of cholesterol is increased in the absence of bile (Dietschy and Gamel, 1971). Patients with complete biliary occlusion, although they apparently do not absorb sterols, continue to excrete some endogenous cholesterol into the faeces (case 13; Norman and Strandvik, 1971), presumably due to mucosal elimination. The biliary output of cholesterol may thus have been markedly decreased (Miettinen and Siurala, 1971) which would explain why the faecal loss of neutral sterols was subnormal in the present study even though absorption of both dietary and endogenous cholesterol was reduced. The increase of faecal neutral sterols in patients on cholestyramine was apparently caused by markedly decreased reabsorption of cholesterol due to impaired micelle formation, particularly because interruption of 
enterohepatic circulation of bile acids by cholestyramine may have decreased the bile aciddependent biliary secretion of cholesterol (Scherstén, Nilsson, Cahlin, Filipson, and Brodin-Persson, 1971). Increased elimination by the mucosa is not excluded, however. Since faecal fat was not significantly increased by the resin, a reduction in lipid absorption which is dependent on micelle formation seems to be more clearly evidenced by faecal sterols than by fat.

\section{BILE ACID METABOLISM}

Earlier studies, recording quantitatively normal biliary secretion of bile acids after the administration of secretin and pancreozymin/cholecystokinin, have suggested that bile acid synthesis was not decreased in patients with liver cirrhosis (Turnberg and Grahame, 1970; Bode et al, 1971). In the present series, however, combined faecal and urinary loss of bile salts under basal conditions and on cholestyramine clearly showed that bile salt production and capacity to augment bile acid synthesis are decreased in liver cirrhosis. In one case raised basal excretion of bile salts was associated with cholestyramine-suppressible diarrhoea, suggesting that the diarrhoea occasionally found in cirrhotic patients may be cholerrhoeic diarrhoea. Interrupted enterohepatic circulation of bile acids in this case is apparently caused by ileal dysfunction, the aetiology of which remains unknown. Though mucosal damage is infrequently seen in the upper small intestine (cf Losowsky and Walker, 1969) its presence in the ileum of this case is not excluded. Increased portal pressure and enhanced intestinal motility could also impair reabsorption of bile acids. Rapid intestinal transit, induced by oral mannitol, has been reported to cause slight bile salt malabsorption (Meihoff and Kern, 1968).

According to earlier studies, bile salts are not present in normal urine, and are not consistently detectable in the urine of cirrhotic patients, biliary occlusion markedly increasing their excretion by this route (Rudman and Kendall, 1957; Gregg, 1968; Norman and Strandvik, 1971). In the present series urinary bile salts were always higher in the patients with cirrhosis than in the normal subjects, and appeared to be very sensitive indicators of impaired parenchymal cell function and/or biliary obstruction. The relative increase in the amount of chenodeoxycholic (plus lithocholic) acid, earlier reported in the urine, serum, and bile of cirrhotic subjects (Rudman and Kendall, 1957; Carey, 1958; Sjövall, 1960; Gregg, 1968), was frequently but not constantly seen in the urinary bile acids of the present series. Enhanced release of newly synthesized primary bile acids from the liver into the blood, and relatively low absorption of secondary bile acids from the intestine (due to a marked reduction in primary bile acids escaping during each enterohepatic circulation into the colon for conversion to secondary products by colonic bacteria) may explain the low percentage of secondary bile acids in the urine of cirrhotic subjects. The amounts of urinary bile acids, especially of secondary ones, decreased significantly on treatment with cholestyramine, indicating that the resin had reduced the escape of bile acids of intestinal origin into the general circulation and that newly synthesized bile acids were not released from the parenchymal cells into the blood stream in increased amounts.

\section{CHOLESTEROL METABOLISM}

The sterol balance data of this series indicated that cholesterol production was decreased in the cirrhotic patients, significantly augmented cholesterol elimination during cholestyramine treatment being balanced either by augmented synthesis or by mobilized tissue cholesterol so that serum cholesterol remained unchanged. The acetate-mevalonate test and serum methyl sterols (precursors of cholesterol) have recently been shown to be good indicators of both increased and decreased cholesterol synthesis in many clinical conditions (Miettinen, 1970, 1971b, c). The results presented here show that in cirrhosis of the liver alterations in cholesterol production are difficult to visualize by these methods; however, relatively low methyl sterol values were found under the basal conditions and a slight increase during cholestyramine treatment as if the stimulation of cholesterol production by the resin had been associated with slightly augmented precursor production as well. The ratio ${ }^{14} \mathrm{C} /{ }^{3} \mathrm{H}$ of the acetatemevalonate test was initially within the control limits, suggesting that the acetate pool was reduced or that the low cholesterol production was associated with a low absolute cholesterol synthesis from both administered acetate and mevalonate, probably owing to a decreased number of hepatic cholesterolsynthesizing cells. In the surviving cells the activity between acetate and mevalonate may be quite high, depending on the overall elimination of cholesterol. Though the augmented cholesterol elimination on cholestyramine may be partly offset by tissue mobilization, synthesis may have increased from both acetate and mevalonate, and so have resulted in the unchanged ${ }^{14} \mathrm{C} /{ }^{3} \mathrm{H}$ ratio and slightly increased methyl sterols in the later steps of the synthesis pathway.

Skilful technical and secretarial assistance given by Mrs E. Gustafsson, Mrs P. Hoffström, and Mrs U. Kaski is acknowledged. The study has been per- 
formed under a contract with the Association of Finnish Life Assurance Companies.

\section{References}

Atkinson, M., Nordin, B. E. C., and Sherlock, S. (1956), Malabsorption and bone disease in prolonged obstructive jaundice. Quart. J. Med., 25, 299-312.

Badley, B. W. D., Murphy, G. M., Bouchier, I. A. D., and Sherlock, S. (1970). Diminished micellar phase lipid in patients with chronic nonalcoholic liver disease and steatorrhea. Gastroenterology, 58, 781-789.

Blum, M., and Spritz, N. (1966). The metabolism of intravenously injected isotopic cholic acid in Laennec's cirrhosis. J. clin. Invest., 45, 187-193.

Bode, C., Goebell, H., and Kehl, W. (1971). Effect of cholecystokinin-Pancreozymin on bile salt secretion into the duodenal juice in patients with liver cirrhosis. Klin. Wschr., 49, 881-883.

Bolin, D. W., King, R. P., and Klosterman, E. W. (1952). A simplified method for the determination of chromic oxide $\left(\mathrm{Cr}_{2} \mathrm{O}_{3}\right)$ when used as an index substance. Science, 116, 634-635.

Carey, J. B., Jr. (1958). The serum trihydroxy-dihydroxy bile acid ratio in liver and biliary tract disease. J. clin. Invest., 37, 1494-1503.

Carlson, L. A. (1963). Determination of serum triglycerides. $J$. Atheroscler. Res., 3, 334-336.

Dietschy, J. M., and Gamel, W. G. (1971). Cholesterol synthesis in the intestine of man: regional differences and control mechanisms. J. clin. Invest., 50, 872-880.

Gregg, J. A. (1968). Urinary excretion of bile acids in patients with obstructive jaundice and hepatocellular disease. Amer. J. clin. Path., 49, 404-409.

Grundy, S. M., Ahrens, E. H., Jr., and Miettinen, T. A. (1965). Quantitative isolation and gas-liquid chromatographic analysis of total fecal bile acids. J. Lipid Res., 6, 397-410.

Grundy, S. M., Ahrens, E. H., Jr., and Salen, G. (1968). Dietary $\beta$-sitosterol as an internal standard to correct for cholesterol losses in sterol balance studies. J. Lipid Res., 9, 374-387.

Hofmann, A. F. (1966). A physicochemical approach to the intraluminal phase of fat absorption. Gastroenterology, 50, 56-64.

Hofmann, A. F., and Borgström, B. (1964). The intraluminal phase of fat digestion in man: the lipid content of the micellar and oil phases of intestinal content obtained during fat digestion and absorption. J. clin. Invest., 43, 247-257.

van de Kamer, J. H., ten Bokkel Huinink, H., and Weyers, H. A. (1949). Rapid method for the determination of fat in feces. J. biol. Chem., 177, 347-355.

Losowsky, M. S., and Walker, B. E. (1969). Liver disease and malabsorption. Gastroenterology, 56, 589-600.

Meihoff, W. E., and Kern, F., Jr. (1968). Bile salt malabsorption in regional ileitis, ileal resection, and mannitol-induced diarrhea. J. clin. Invest., 47, 261-267.

Miettinen, T. A. (1970). Detection of changes in human cholesterol metabolism. Ann. clin. Res., 2, 300-320.
Miettinen, T. A. (1971a). Mechanism of fat malabsorption in patients with liver cirrhosis. (Abstr.) Scand. J. clin. Lab. Invest., 27, Suppl. 116, 56.

Miettinen, T. A. (1971b). Serum methyl sterols and their distribution between major lipoprotein fractions in different clinical conditions. Ann. clin. Res., 3, 264-271.

Miettinen, T. A. (1971c). Relationship between faecal bile acids, absorption of fat and vitamin $B_{19}$, and serum lipids in patients with ileal resections. Europ. J. clin. Invest., 1, 452-460.

Miettinen, T. A., Ahrens, E. H., Jr., and Grundy, S. M. (1965). Quantitative isolation and gas-liquid chromatographic analysis of total dietary and fecal neutral steroids. J. Lipid Res., 6, $411-424$.

Miettinen, T. A., and Luukkainen, T. (1968). Gas-liquid chromatographic and mass spectrometric studies on sterols in vernix caseosa, amniotic fluid and meconium. Acta chem. scand., 22, 2603-2612.

Miettinen, T. A., and Siurala, M. (1967). Distribution of lipids into micellar and oil phases during fat absorption under normal and pathological conditions. (Abstr.) Scand. J. clin. Lab. Invest., 19, Suppl. 95, 69.

Miettinen, T. A., and Siurala, M. (1971). Micellar solubilization of intestinal lipids and sterols in gluten enteropathy and liver cirrhosis. Scand. J. Gastroent., 6, 527-535.

Morgan, R. G. H., and Borgström, B. (1969). The mechanism of fat absorption in the bile fistula rat. Quart. J. exp. Physiol., 54, 228-243.

Norman, A., and Strandvik, B. (1971). Formation and metabolism of bile acids in extrahepatic biliary atresia. J. Lab. clin. Med., 78, 181-193.

Palmer, R. H. (1967). The formation of bile acid sulfates: a new pathway of bile acid metabolism in humans. Proc. nat. Acad. Sci., 58, 1047-1050.

Pearson, S., Stern, S., and McGavack, T. H. (1953). A rapid, accurate method for the determination of total cholesterol in serum. Analyt. Chem., 25, 813-814.

Porter, H. P., Saunders, D. R., Tytgat, G., Brunser, O., and Rubin, C. E. (1971). Fat absorption in bile fistula man: a morphological and biochemical study. Gastroenterology, 60, 1008-1019.

Rudman, D., and Kendall, F. E. (1957). Bile acid content of human serum. I. Serum bile acids in patients with hepatic disease. J. clin. Invest., 36, 530-537.

Scherstén, T., Nilsson, S., Cahlin, E., Filipson, M., and BrodinPersson, G. (1971). Relationship between the biliary excretion of bile acids and the excretion of water, lecithin, and cholestero in man. Europ. J. clin. Invest., 1, 242-247.

Shapiro, A., Koster, H., Rittenberg, D., and Schoenheimer, R. (1936). The origin of fecal fat in the absence of bile, studied with deuterium as an indicator. Amer. J. Physiol., 117, 525-528.

Siperstein, M. D., Chaikoff, I. L., and Reinhardt, W. O. (1952) $\mathrm{C}^{14}$-cholesterol. V. Obligatory function of bile in intestinal absorption of cholesterol. J. biol. Chem., 198, 111-114.

Sjövall, J. (1960). Bile acids in man under normal and pathological conditions. Clin. chim. Acta., 5, 33-41.

Turnberg, L. A., and Grahame, G. (1970). Bile salt secretion in cirrhosis of the liver. Gut, 11, 126-133. 